\title{
Ionospheric Simulation Compared With Dynamics Explorer Observations for November 22, 1981
}

\author{
J. J. SoJka, ${ }^{1}$ M. Bowline, ${ }^{1}$ R. W. Schunk, ${ }^{1}$ J. D. Craven, ${ }^{2}$ L. A. Frank, ${ }^{2}$ J. R. Sharber, ${ }^{3}$ \\ J. D. WinNINGHAM, ${ }^{3}$ AND L. H. BRACE ${ }^{4}$
}

\begin{abstract}
Dynamics Explorer (DE) 2 electric field and particle data have been used to constrain the inputs of a timedependent ionospheric model (TDIM) for a simulation of the ionosphere on November 22, 1981. The simulated densities have then been critically compared with the DE 2 electron density observations. This comparison uncovers a model-data disagreement in the morning sector trough, generally good agreement of the background density in the polar cap and evening sector trough, and a difficulty in modelling the observed polar $F$ layer patches. From this comparison, the consequences of structure in the electric field and precipitation inputs can be seen. This is further highlighted during a substorm period for which DE 1 auroral images were available. Using these images, a revised dynamic particle precipitation pattem was used in the ionospheric model; the resulting densities were different from the original simulation. With this revised dynamic precipitation model, improved density agreement is obtained in the auroral/polar regions where the plasma convection is not stagnant. However, the dynamic study also reveals a difficulty of matching dynamic auroral patterns with static empirical convection patterns. In this case, the matching of the models produced intense auroral precipitation in a stagnation region, which, in tum, led to exceedingly large TDIM densities.
\end{abstract}

\section{INTRODUCTION}

Theoretical models of the terrestrial ionosphere and thermosphere have now attained global-scale [Sojka and Schunk, 1985; Roble et al., 1987; Fuller-Rowell et al., 1987]. Such models require global-scale inputs, especially for the magnetospheric parameters. At the present time, no globalscale theoretical model of the magnetosphere exists. Hence, statistical (empirical) models of the magnetospheric electric field [Volland, 1978; Heelis et al., 1982; Sojka et al., 1986; Heppner and Maynard, 1987] and auroral precipitation [Spiro et al., 1982; Hardy et al., 1985; Evans, 1987] are used as inputs to ionospheric and thermospheric models. Such studies are handicapped because statistical inputs cannot readily be adapted to simulate the spatial variations and temporal dynamics of geomagnetic storms and substorms. To minimize some of these difficulties, models have used in situ satellite observations of auroral precipitation and electric fields, combined with Defense Meteorological Satellite Program (DMSP) images and ground-based incoherent scatter radar observations of electric fields, to define the auroral and convection boundaries [Sojka et al., 1983; Rasmussen et al., $1986 \mathrm{~b}$ ]. With the availability of global auroral images from the Dynamics Explorer 1 (DE 1) satellite, it is possible to directly define a magnetospheric auroral input on the scale needed by the ionospheric and thermospheric models.

In a previous study, we investigated methods to provide a description of the energy flux and characteristic energy of the auroral precipitation based on DE 1 images [Sojka et al.,

\footnotetext{
${ }^{1}$ Center for Atmospheric and Space Sciences, Utah State University, Logan, Utah.

${ }^{2}$ Department of Physics and Astronomy, University of Iowa, Iowa City, Iowa.

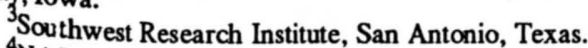

${ }^{4}$ NASA Goddard Space Flight Center, Greenbelt, Maryland.

\section{Copyright 1992 by the American Geophysical Union.}

Paper number $91 \mathrm{JA} 02215$.

0148-0227/92/91JA-02215\$05.00
}

1989]. The resulting precipitation models were compared with in situ DE 2 particle measurements. Rees et al. [1988] have carried out image-to-precipitation calculations and used similar in situ cross checks on the auroral precipitation. In our previous study, a particularly dynamic auroral period was chosen because it provided excellent image sensitivity. Unfortunately, the magnetospheric convection was also dynamic, and because of the northward turning of the interplanetary magnetic field (IMF) during the selected period, a realistic convection model could not be defined. The study did, however, show the ionospheric dependence on the auroral dynamics.

For this study we used a period where both the precipitation and convection patterns could be compared with DE data. In addition, the IMF data were available and were found to be reasonably behaved.

Section 2 describes the selected data period, while section 3 describes the quiet day inputs and model-observation comparison. In section 4, the major substorm disturbance in this period is analyzed. Results of this study are summarized in section 5 .

\section{NOVEMBER 22, 1981}

This day was selected for a variety of reasons based upon both data availability and geomagnetic conditions. During this 24-hour period, the 3-hourly $K_{p}$ dropped from $3+$ to 2 (see top panel in Figure 1); the average 3 -hourly $K_{p}$ was $2+$. Several substorms occurred during this day as shown by the short duration peaks in the $A E$ index in the bottom panel of Figure 1. Between 0730 and 0935 UT at least two substorms occurred and the $A E$ reached values of 750 during this time. This was the strongest disturbance; for the rest of the period the $A E$ index averaged around 200 with brief departures to nearly 500 , these departures being associated with other smaller substorms. Because these substorms were of only moderate intensity they would not lead to a significant perturbation of the auroral $F$ region. At 0150,1540 , and 2300 UT the DE 1 auroral images show the substorms and confirm they are moderate compared with the 0730 and 0900 UT 

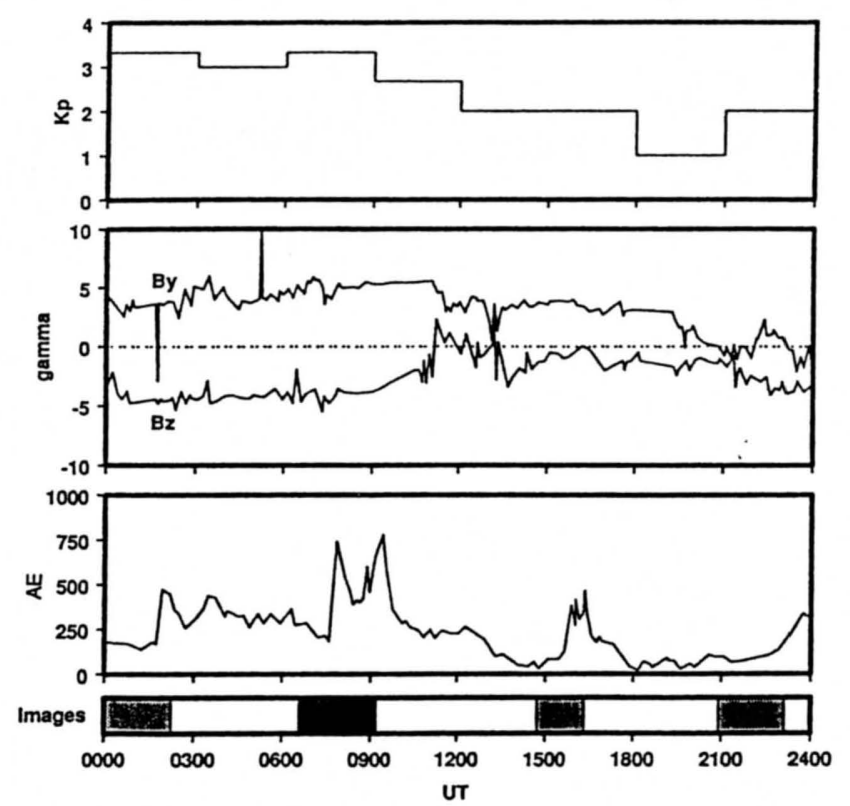

Fig. 1. Geomagnetic and IMF indices for November 22, 1981, and a chart indicating when DE 1 auroral images were available (gray shading on the UT axis). The 3-hourly $K_{p}$ index is plotted in the top panel, while the auroral electroject index, $A E$, is plotted in the bottom panel. Two components of the IMF, $B_{y}$ and $B_{z}$, are plotted in the middle panel.

substorms. Hence, the 0730 to the 0935 UT period will be considered in detail as a substorm period, while the other substorms will be averaged over and considered as a quiet period.

The IMF data were also available, and two components are shown in Figure 1 (middle panel). For almost the entire period the IMF had the same sector morphology, namely, southward IMF with $B_{y}$ positive. In Figure 1 (middle panel), the $B_{y}$ component is about $4 \mathrm{nT}$ (gamma) positive until about 2100 UT, when it approaches zero, and then it oscillates about this value for the remaining 3 hours. The $B_{z}$ component is negative (southward) all day with the exception of a 1-hour period from 1030 to 1130 UT. During this brief period, the $B_{z}$ component is weakly positive, less than $1 \mathrm{nT}$. There appears to be no correlation between the northward turning at $\sim 1130$ and subsequent southward turning of the IMF at 1330 UT and the substorms, as indicated by the $A E$ index. However, the decreasing $K_{p}$ is probably correlated with the $B_{z}$ component approaching zero from its initial $-5 \mathrm{nT}$ value.

The IMF southward condition implies that a two-cell convection pattern is appropriate, while the long period of $B_{y}$ positive implies that the convection pattern would have a well-defined skewing. This corresponds to the Heppner and Maynard [1987] BC pattern. In our previous DE TDIM study [Sojka et al., 1989], it was not possible to define the convection pattern. However, this study begins with the convection pattern established; this will be demonstrated in the next section.

A further reason for selecting this period was the availability of $\mathrm{DE} 1$ auroral images from the spin-scan auroral imager (SAI) instrument. The shaded bars on the UT time axis of Figure 1 indicate the four periods for which auroral images were taken. Our attention will be focused upon the 0635 to 0935 UT period when substorms were present. A third reason for focusing on this day was that it can be well represented by a "quiet" day with a 3-hour substorm period superimposed, Finally, during this 24-hour period, data were available from a number of DE 2 orbits for almost all the instruments.

\section{QUIET DAY STUDY}

November 22, 1981 can be characterized as a quiet day with a superimposed pair of substorms occurring at 0730 and 0900 UT. In this section, the quiet day aspect of this 24-hour period will be analyzed. Data from several instruments on DE 2 will be used to help define the magnetospheric drivers for the ionosphere and, subsequently, to compare the model ionospheric densities with the in situ observed densities. During this 24-hour period, data are available from 11 partial DE 2 orbits out of a possible 15 orbits. Five of these northern hemisphere passes have been selected for detailed presentation because complete data sets for the vector electric field instrument (VEFI), low altitude plasma instrument (LAPI), and Langmuir probe (LANG) are available. These five orbits represent the variability found during this 24 -hour period, including one pass during the substorm. Figure 2 shows the selected passes, approximated as straight lines, in the polar magnetic coordinates with a Hardy et al. [1985] auroral oval shown as the shaded region. Each DE 2 passage is labeled with the approximate time at which the orbit crossed the dawnside northern high-latitude region. This time will be used as the reference for discussions about specific orbits.

\subsection{Electric Field}

Data from the VEFI instrument were used to verify the use of the Heppner and Maynard [1987] BC electric field model (HM$\mathrm{BC}$ ) to simulate plasma convection on this day. The DE 2 ac and dc electric field instrumentation [Maynard et al., 1981] was designed for three-axis measurements using the symmetric double-probe floating potential technique with cylindrical antennas providing 21.4-m baselines. As described by Maynard et al. [1982], the $\mathrm{Z}$ axis (east-west geographic)

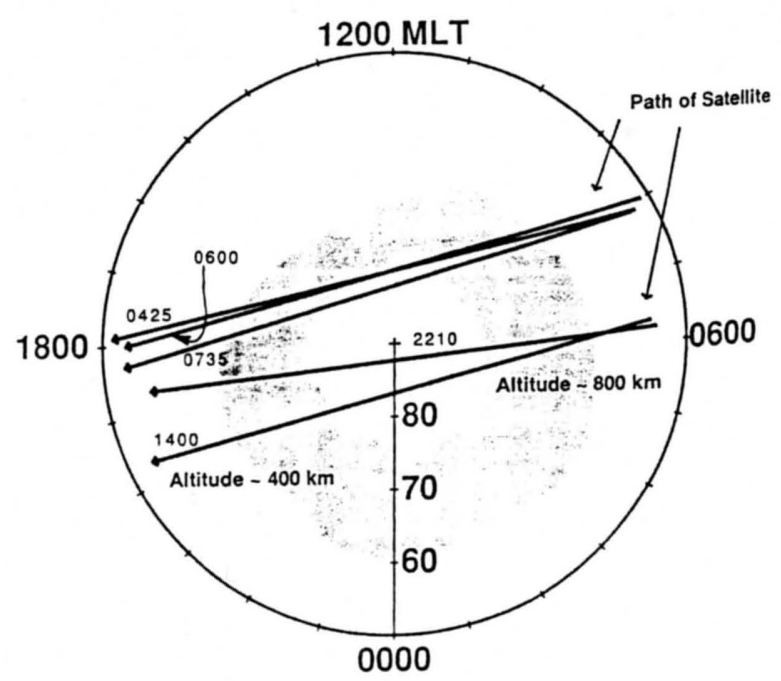

Fig. 2. DE 2 orbit tracks in the northem hemisphere in dipole latitudeMLT coordinates in a polar format. These five orbits are used to highlight the electric field and particle precipitation data. In the dawn sector, the DE 2 altitude is about $800 \mathrm{~km}$, decreasing to below $400 \mathrm{~km}$ in the dusk sector. A Hardy et al. [1985] $K_{p}=3$ oval is shown for reference, as the shaded region. The shading corresponds to energy fluxes larger than $0.25 \mathrm{ergs} \mathrm{cm}^{-2} \mathrm{~s}^{-1}$. 
antenna failed to deploy; hence, measurements were restricted to the two components in the orbit plane. The dc data for most purposes are presented in spacecraft coordinates in which the two components are resolved into a horizontal component $E_{x}$ (positive in the direction of the spacecraft velocity vector) and a vertically upward component. A correction for contact potentials is determined for each pass using an assumption that the $45^{\circ}$ latitude points are at zero potential. For presentation and analysis, the $E_{x}$ component is examined after $\mathbf{v} \times \mathbf{B}$ fields from the satellite's motion and corotation have been removed.

From Figure 2 it can be argued that the missing electric field component on this day is of secondary importance because the orbits lie primarily along the dawn-dusk meridian. The dominant electric field component in this region is along the VEFI $E_{x}$ direction. This electric field component is available, and hence, its path integral gives a reasonable approximation to the cross-polar-cap potential. For this day there are no DE 2 retarding potential analyzer (RPA) data to infer the missing electric field component.

Five passes of VEFI data were compared with the Heppner and Maynard [1987] BC electric field model. Figure 3 shows
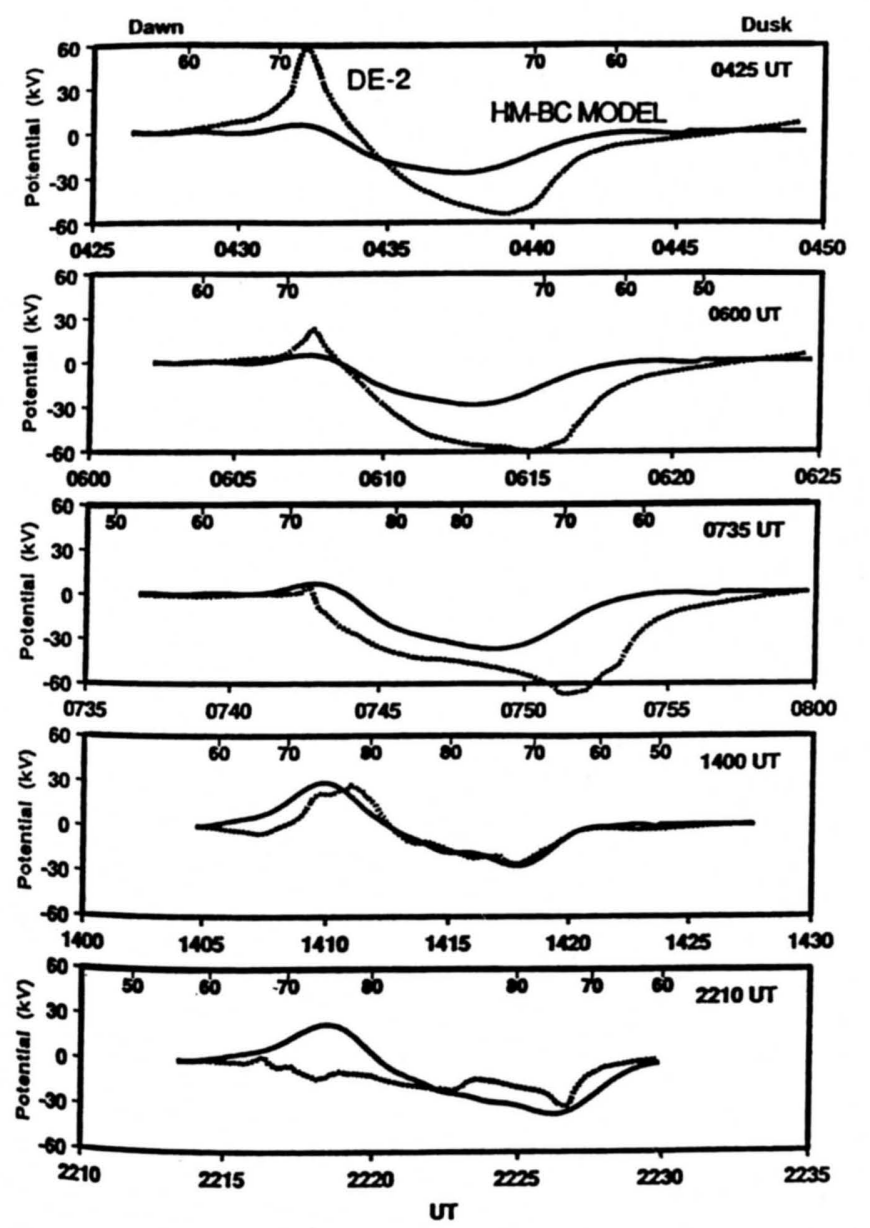

Fig. 3. Electric potential along the DE 2 satellite track for five northern hemisphere passes on November 22, 1981. The electric potential computed from the VEFI electric field data (dashed line) is compared with that from the Heppner and Maynard [1987] BC $K_{p}=3$ model (solid line). The five satellite tracks are shown in Figure 2 . Magnetic latitude is given along the satellite track by the axis at the top of each from . Each satellite track progresses across the northem polar region from dawn toward dusk. the comparison between the VEFI and HM-BC electric potential for the five orbits shown in Figure 2. In this figure, each panel corresponds to a single pass and is labeled with the orbit time. The HM-BC pattern has the strong electric field in the dawn sector of the polar cap; this asymmetry is associated with the positive IMF $B_{y}$. In the potential plots shown in Figure 3, the strong electric fields are associated with regions of large gradients in the potential. The VEFI data, especially the top two panels, show even larger asymmetries in the electric field. This is consistent with the IMF data (Figure 1), which shows that the $B_{y}$ component is strongest for the first 8 hours of this day. Toward the end of this period, later than $2100 \mathrm{UT}$, the IMF $B_{z}$ and $B_{y}$ components become very weak and the convection pattern is expected to depart from the BC pattern. This change is also manifested in the decrease in $K_{p}$ (Figure 1). The Heppner and Maynard potential patterns have been parameterized and made $K_{p}$ dependent by Rich and Maynard [1989], but we have not included this variation in our simulation. In this instance, we believe that the departure from the $\mathrm{BC}$ convection pattern as $B_{z}$ approaches zero is more significant than the $30 \%$ reduction in $K_{p}$, and because we do not know how the convection pattern changed, we adopt a constant BC pattern for the quiet period. The comparison of the electric potential magnitude is best at the latter times when the $K_{p}$ is lower. At the earlier times, the electric potential variations observed by VEFI are larger than the BC model. Better agreement is not obtained by simply changing the $K_{p}$, because the model smooths out these regions of strong electric fields.

\subsection{Auroral Precipitation}

The Hardy et al. [1985] auroral precipitation model for $K_{p}=$ 3 was compared with the DE 2 plasma observations. The LAPI instrument on DE 2 consisted of 15 divergent parabolic-plate electrostatic analyzers, each of which provided differential spectral measurements of electrons and positive ions over the energy range from $\sim 5 \mathrm{eV}$ to $\sim 30 \mathrm{keV}$ with a 1-s temporal resolution. The analyzer fields of view were selected to provide optimal sampling within and outside of the particle source and loss cones at DE 2 altitudes $(500-1000 \mathrm{~km})$. For the observations on November 22, 1981, 31-point energy spectral measurements were made for electrons at pitch angles $0^{\circ}, 7.5^{\circ}, 15^{\circ}, 30^{\circ}, 45^{\circ}, 60^{\circ}, 105^{\circ}, 135^{\circ}, 165^{\circ}$, and $172.5^{\circ}$. Further details and calibration information on LAPI are given by Winningham et al. [1981].

For each LAPI spectrum, the precipitating electron energy flux from 50 to $20,000 \mathrm{eV}$ was integrated to give an auroral energy flux. Figure 4 shows these energy fluxes for the five selected orbits. Also shown in this figure is the Hardy et al. [1985] $K_{p}=3$ energy flux at the satellite locations. The auroral precipitation is both more structured and more confined than the statistical oval. For the first half of the day, the LAPI observations are comparable to the model predictions in the oval regions. However, toward the end of the day as the activity decreases (see Figure 1), the LAPI data show lower fluxes of precipitating electrons than the model. In the first three passes shown in Figure 4, the model fluxes are in conflict with the observations in the polar region, i.e., no precipitation is observed while the model suggests about 0.2 erg $\mathrm{cm}^{-2} \mathrm{~s}^{-1}$ should be present. This discrepancy is not severe when it is realized that these three passes are not truly in the polar cap, but just touch the dayside cusp region (see Figure 2). 

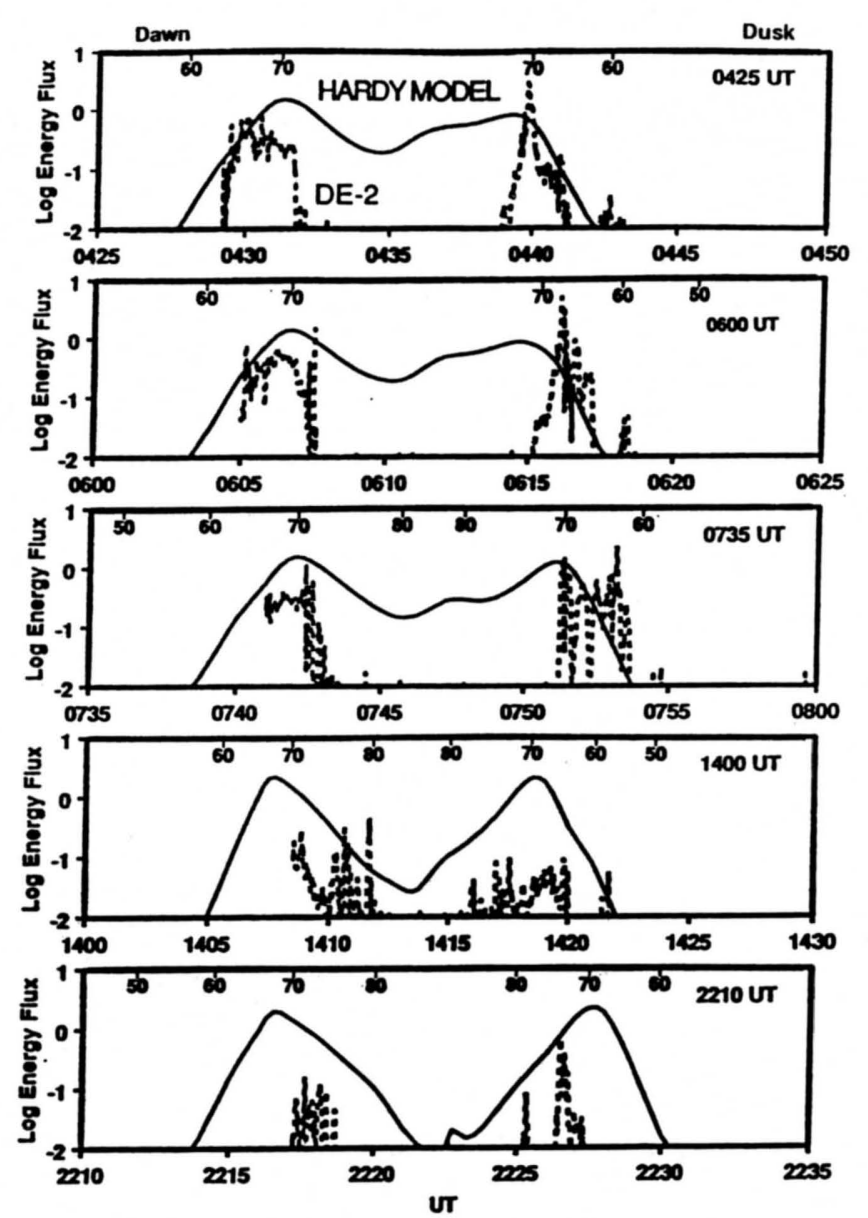

Fig. 4. Electron precipitation flux along the DE 2 satellite track for five northem hemisphere passes on November 22, 1981. The precipitation flux computed from the LAPI electron instrument (dashed line) is compared with that from the Hardy et al. [1985] $K_{p}=3$ model (solid line). The energy flux is in ergs per square centimeter per second. The five satellite tracks are identical to those used in Figure 3 and shown in Figure 2. Magnetic latitude is given along the satellite track by the axis at the top of each panel. Each satellite track progresses across the northem polar region from dawn toward dusk.

In this region, the difficulty of using a statistical model is highlighted by the model's dayside oval being significantly wider in latitude than was actually present. The remaining two orbits do cross the polar cap, and the fluxes do decrease as expected (see Figure 4, bottom two panels). Hence, the polar cap problem in the first three passes in Figure 4 indicates that the actual oval was somewhat more expanded on the dayside than the $K_{p}=3$ oval we have adopted. This is consistent with the magnetic indices, which were initially at a $K_{p}=3+$ level. For the purposes of this study, the $K_{p}=3$ oval appears to be reasonable, and hence, we adopted the Hardy et al. $K_{p}=3$ model to describe the auroral precipitation for the quiet day and for consistency with the adoption of a fixed convection pattern.

\subsection{Ionospheric Model}

Our ionospheric model was initially developed as a midlatitude, multi-ion $\left(\mathrm{NO}^{+}, \mathrm{O}_{2}{ }^{+}, \mathrm{N}_{2}{ }^{+}\right.$, and $\left.\mathrm{O}^{+}\right)$model by Schunk and Walker [1973]. The time-dependent ion continuity and momentum equations were solved as a function of altitude for a corotating plasma flux tube including diurnal variations and all relevant $E$ and $F$ region processes. This model was extended to include high-latitude effects due to convection electric fields and particle precipitation by Schunk et al. [1975, 1976]. A simplified ion energy equation was also added which was based on the assumption that local heating and cooling processes dominate (valid below $500 \mathrm{~km}$ ). The trajectories for plasma motion were determined as the plasma moved in response to convection electric fields. A further extension of the model to include the minor ions $\mathrm{N}^{+}$and $\mathrm{He}^{+}$, an updated photochemical scheme, and the mass spectrometer/incoherent scatter (MSIS) atmospheric model is described by Schunk and Raitt [1980].

The addition of "constant" plasma convection and empirical models for particle precipitation is described by Sojka et al. $[1981 a, b]$. More recently, the ionospheric model has been extended by Schunk and Sojka [1982] to include ion thermal conduction and diffusion-thermal heat flow so that the ion temperature is now rigorously calculated at all altitudes between 120 and $1000 \mathrm{~km}$. The adopted ion energy equation and conductivities are those given by Conrad and Schunk [1979]. Also, time-dependent plasma convection and particle precipitation inputs have been used with the basic highlatitude model so that magnetospheric storm and substorm conditions could be studied [Sojka and Schunk, 1983, 1984].

For the quiet day aspect of this study, the ionospheric model described above was run for a 24-hour period during which the magnetospheric and solar inputs were fixed. This produced a "diurnally reproducible" electron density data set. The solar conditions were represented by a solar flux $F 10.7$ value of 180 . Based upon the indices in Figure 1 and the DE data shown in the previous two sections, the magnetospheric inputs (convection and precipitation) were, respectively, the Heppner and Maynard [1987] BC model and the Hardy et al. [1985] $K_{p}=$ 3 model. Since both of these models are extensively discussed in the respective references, no further discussion is given here. A neutral atmosphere is also needed; the MSIS model was used for this input [Hedin, 1987]. For the MSIS model, the aforementioned $F 10.7$ value and $A p=11$ were used as input parameters. A simple meridional $200 \mathrm{~m} \mathrm{~s}^{-1}$ neutral wind model blowing from $1300 \mathrm{MLT}$ to $0100 \mathrm{MLT}$ was adopted for the dark polar regions. The validity of this wind is difficult to quantify, since no IMF dependent wind model is presently available. Rees and Fuller-Rowell [1989] used their coupled thermosphere and ionosphere to study the IMF $B_{y}$ dependence of the high latitude. At latitudes poleward of $\sim 75^{\circ}$, a strong asymmetry is found in the $F$ region neutral wind as a function of IMF $B_{y}$, but at latitudes equatorward of this a meridional wind peaking at 0100 MLT is found. Since the wind affects the $F$ layer only at the latitudes equatorward of $75^{\circ}$, this simple wind is consistent with that from the more physical coupled ionospherethermosphere model. The TDIM produced a data base of electron densities for magnetic latitudes poleward of $50^{\circ}$ over the 100 to $800 \mathrm{~km}$ altitude range.

The quiet day ionospheric simulation for November 22 , 1981 is shown in Plate 1 as a UT series of snapshots of $N_{m} F_{2}$ (top row), $h_{m} F_{2}$ ( second row), molecular ion density at $300 \mathrm{~km}$ (third row), and $\mathrm{O}^{+}$at $800 \mathrm{~km}$ (bottom row). Six UT snapshots uniformly distributed throughout the day are shown. $N_{m} F_{2}$ indicates how significant the UT control of the polar ionosphere is: at 0100 UT the polar densities are below $4 \times$ $10^{5} \mathrm{~cm}^{-3}$, while at 1700 UT the polar densities everywhere approach $1 \times 10^{6} \mathrm{~cm}^{-3}$. Apart from the absolute density 

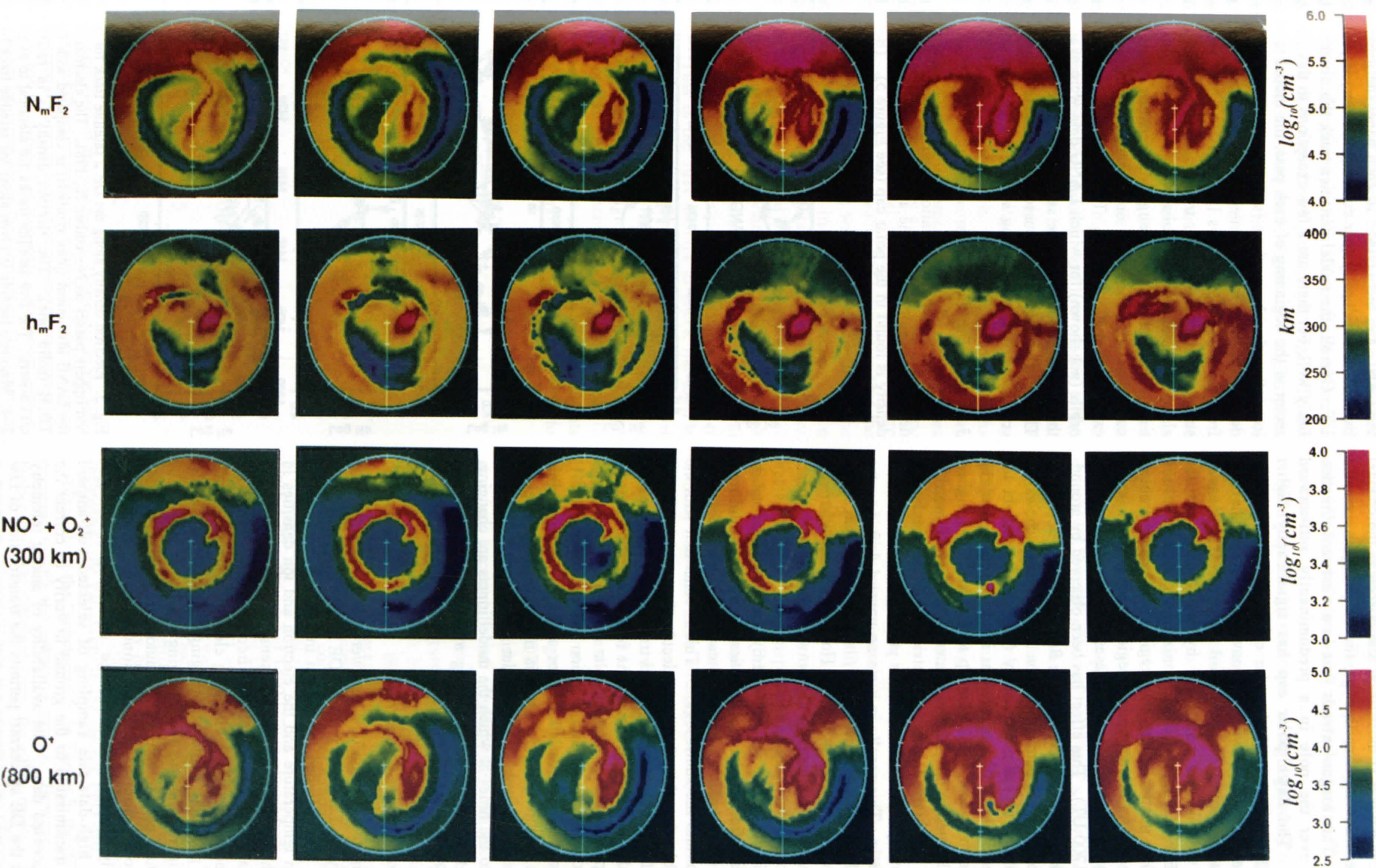

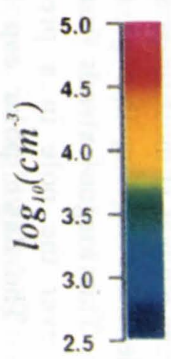

Plate 1. Color-coded snapshots of the quiet day ionospheric simulation at six equally spaced times. Top row corresponds to $N_{m} F_{2}$, 2nd row to $h_{m} F_{2}$, 3rd row to the molecular ion density at $300 \mathrm{~km}$, and the bottom row to the electron density at $800 \mathrm{~km}$. Data are color-coded in magnetic latitude-MLT polar format from $50^{\circ}$ to the pole. The polar dial format is identical to that used in Figures 2, 6, and 9. Color keys are given on the right side of each row. 
differences, the polar cap density is structured. A "tongue of ionization" is evident at most times and is seen as the channel of high densities moving through the cusp region into the polar cap. This tongue extends first in a westward direction and then over the pole in a predominantly antisunward direction. The dawn polar cap has significantly higher densities than does the dusk polar cap. All these density structures are associated with the convection pattern, the IMF $B_{y}$ positive Heppner and Maynard pattern. The density variation with UT is controlled by the location of the transition from daylight produced ionization to darkness (solar terminator) in relation to the cusp region where plasma enters the polar cap. As this terminator region approaches the cusp, the density in the polar cap increases (compare densities at 0500 and 1700 UT). This effect has been observed by groundbased incoherent scatter radars [de la Beaujardière et al., 1985].

The second row of panels from the top in Plate 1 shows the height of the $F$ region peak density $\left(h_{m} F_{2}\right)$. In sunlight the peak lies just below $300 \mathrm{~km}$, whereas inside the dark polar cap it ranges from as low as $220 \mathrm{~km}$ up to $400 \mathrm{~km}$. The highest values are located in the polar cap dawn sector just poleward of the cusp. In this region, the electric fields are the largest (largest flow speeds) and the flow is predominantly toward the magnetic pole. This results in a strong upward drift, i.e., the electric field is perpendicular to the tilted magnetic field which gives rise to an upward $\mathbf{E} \times \mathbf{B}$ drift. However, on the other side of the pole, this flow leads to a downward drift which appears as the region of lowest $h_{m} F_{2}$ values.

In the vicinity of the peak $(300 \mathrm{~km})$, the molecular ions do not show significant polar cap densities or structure (third row, Plate 1). The molecular ions instead are enhanced in the auroral oval and the sunlit region. This is consistent with the fast recombination time for the molecular ions which inhibits transport effects. Only a very small transport enhancement in the molecular ions can be seen in the region of the high $h_{m} F_{2}$ where the plasma moves into the polar cap.

At $800 \mathrm{~km}$, the ion density variation (bottom panel, Plate 1) is similar to the $N_{m} F_{2}$ variation. For a diurnally reproducible study such as this quiet day, this is not surprising since the topside time constant, on the order of an hour, is "fast" compared to the times at which the model inputs are changing. This would not be the case during a substorm [Sojka and Schunk, 1983, 1984].

\subsection{Electron Density Comparison}

The computed electron densities were compared with those measured by the Langmuir probe on DE 2 . The Langmuir probe instrument was designed to perform in situ measurements of the electron temperature and the electron and ion densities in the ionosphere. Two independent sensors were connected to individual adaptive sweep voltage circuits, and hence, the LP can continuously track the changing electron temperature and spacecraft potential while autoranging electrometers adjust their gain in response to the changing plasma density. The control signals used to achieve this automatic tracking provide a continuous monitor of the ionospheric parameters. Additionally, internal data storage circuits permit highresolution, high-data-rate sampling of selected volt-ampere curves for transmission to the ground to verify or correct the inflight processed data. The availability of analog telemetry channels in the DE spacecraft permits the transmission of raw electrometer data from either of the two sensors. Further details are given by Krehbiel et al. [1981].
Figure 5 shows the electron density along the five orbits for the LANG and the TDIM. In each panel the logarithm to the base 10 of the density (per cubic centimeter) is plotted against UT. Overall, the model densities track the observed densities fairly well, but there are a few exceptions to this. In the dawn sector at the beginning of each pass, the model is consistently lower than the observations (see arrows labeled A). The LANG density structure in the center of the polar cap is also missing from the model (see arrows labeled B), and the location of the structure in the dusk sector trough (arrows labeled C) does not always coincide with the observed location. Ignoring, for the time being, the dawn trough discrepancy (A), the density comparison for these five orbits ranges from good to almost excellent (orbit 1400 UT). This is also the case for the other orbits (not shown) for which LANG data were available where the differences fall into the same categories found in Figure 5. These differences are discussed and related to the geophysical conditions in the following section.

\subsection{Quiet Day Discussion}

Both the LANG observations and the model show that the density does not peak in the auroral region, but rather the peak density is found in the polar cap (see Figure 5). This is because

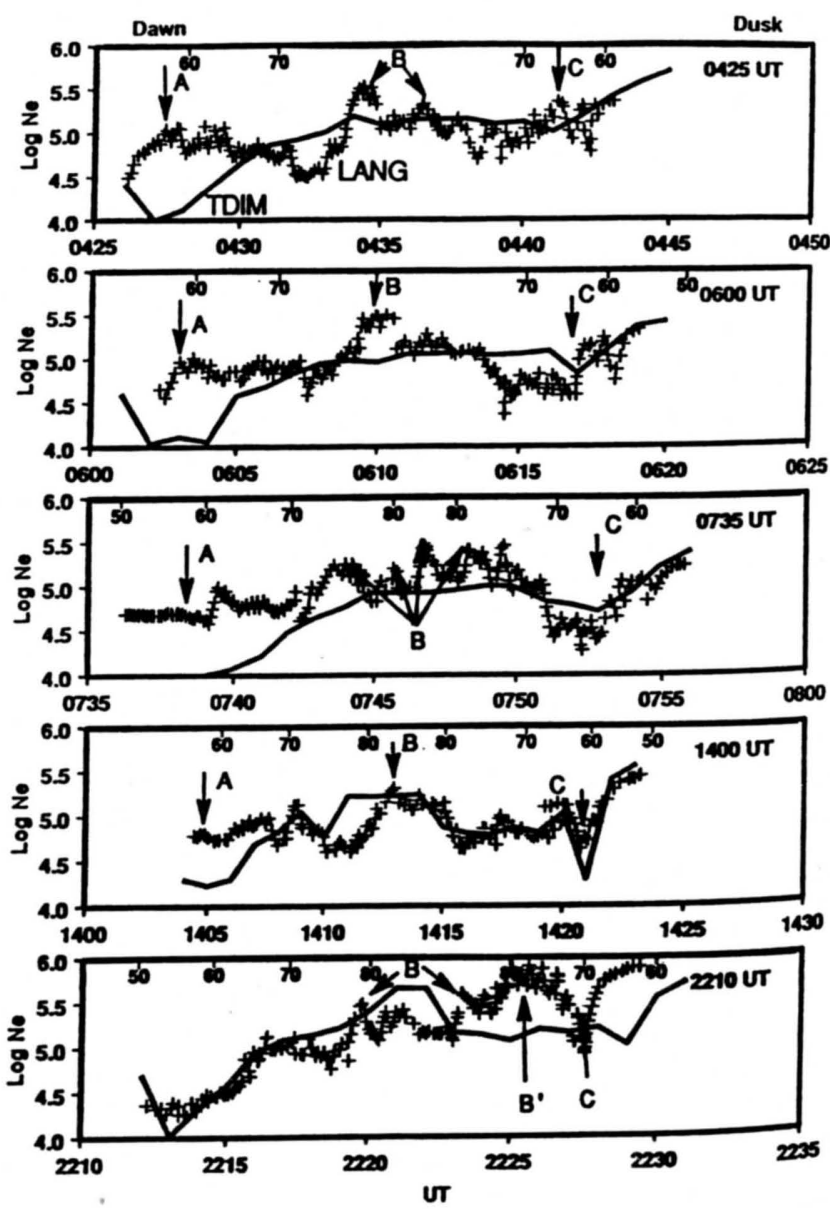

Fig. 5. Electron density along the DE 2 satellite track for five northern hemisphere passes on November 22, 1981. The electron density from the LANG instrument (plus symbols) is compared with that from the TDIM (solid line). The electron density is in reciprocal cubic centimeters. The five satellite tracks are identical to those in Figures 2-4. Magnetic latitude is given along the satellite track by the axis at the top of each panel. Each satellite track progresses across the northem polar region from dawn toward dusk. 
the densities are all in the topside ionosphere at the satellite altitude where the role of plasma transport is more important than that of the auroral precipitation [Sojka and Schunk, 1984]. The DE 2 altitude ranges from $800 \mathrm{~km}$ on the dawnside to $400 \mathrm{~km}$ on the dusk end of each passage (see Figure 2), and hence, the measurements were made above the $F$ region peak. Agreement is also present in the dynamic range of the observed densities with, of course, the exception of the dawn trough region.

The disagreement in observed and modelled densities found in the morning sector trough region was unexpected since this region is believed to be relatively independent of the magnetospheric inputs. Figure 6 shows the relevant ionospheric morphology in this region. A circle represents the region where the model densities are low relative to the LANG densities. This circle is located equatorward of the nocturnal auroral region and is in darkness; the straight line represents the solar terminator. Passing through this region is the 0735 UT DE 2 satellite track. In the TDIM, the plasma present in the large circle has corotated to this region from around midnight. During this corotation the plasma flux tubes have remained equatorward of the auroral oval (see dashed line in Figure 6). These corotational and auroral conditions are consistent with the VEFI observations (Figure 3 ) in that the electric potential is not changing with latitude $(E \approx 0)$ and the LAPI (Figure 4) data, which indicates the region to be equatorward of the auroral precipitation. The TDIM densities in these flux tubes are maintained by the upward induced drift caused by the generally equatorward neutral winds. Although this mechanism is adequate to maintain the ionosphere around midnight, it is unable to do so just prior to sunrise [Sojka et al., 1981b]. This is the first attempt to check the topside densities in the trough at these presunrise times. The model densities are clearly too low in this region for the first four orbits shown in Figure 5, although the final orbit does agree better with the model. An extensive check has been made to confirm that the observed densities are accurate, and LANG data from other days confirm this trend. This result has led us to

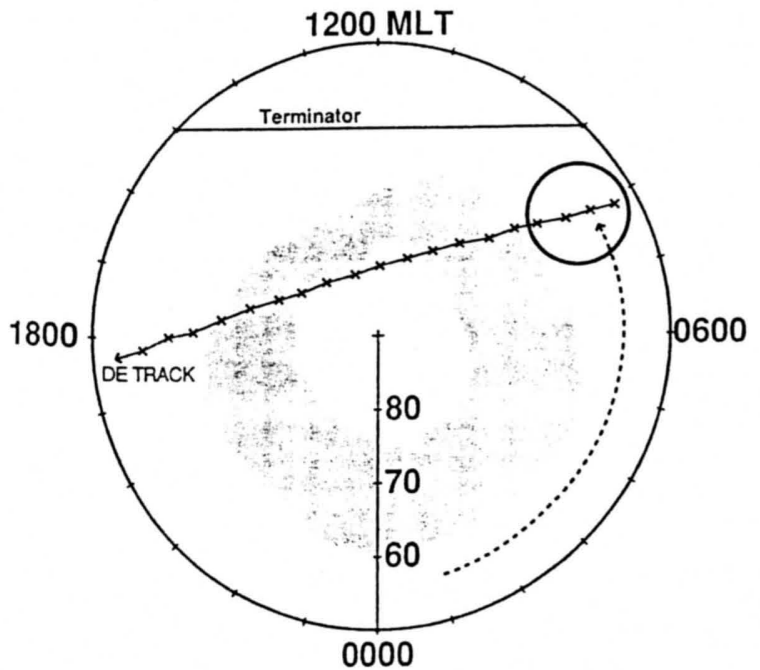

Fig. 6. Schematic view of the plasma-DE 2 geometry in the lowdensity predawn trough region plotted in a dipole latitude-MLT polar format. This region is shown as a circle on the line representing a DE 2 satellite track, and the dashed line represents a corotational plasma trajectory. The shaded region shows the Hardy et al. [1985] auroral oval, while the terminator is shown as the solid line across the dayside. The format is the same as for a single panel of Figure 5 . begin a follow-up study to determine what is missing in the TDIM nighttime trough processes. The obvious candidate is a downward plasma flux from the plasmasphere, which was set to zero in the simulation owing to a lack of measurements of this parameter.

Polar cap density structures, as highlighted by the B arrows in Figure 5, are not expected to be present in the TDIM. The model uses only statistically smooth inputs for the magnetospheric convection and precipitation, and hence, no source for multiple structures in the polar cap is present. However, this picture is somewhat over simplified; certain aspects of the structure can be related to the presently used inputs. For the first two orbits in Figure 5, the first B arrow points to a region in the polar cap where the density increases from about $3 \times 10^{4}$ to $3 \times 10^{5} \mathrm{~cm}^{-3}$ over a very small distance. Figure 3 VEFI data show that this is the region of largest electric fields in the polar cap. These measured electric fields are stronger than those obtained from the HM-BC input to the TDIM simulation. These electric fields are responsible for convecting plasma through the cusp region into the polar cap. The polar cap density features then depend upon the plasma and convection in the vicinity of the cusp. Such a cusp control can be seen in $N_{m} F_{2}$ as a function of UT in Plate 1. These convecting density structures have been reported [Weber et al., 1984,1986 ] and are referred to as $F$ layer patches. Morphologically, they are present during IMF southward conditions, while their sizes and locations depend on the $v$ ariability in the cusp convection in ways not fully understood. Earlier TDIM ionospheric studies have shown that significant polar cap density structuring is possible even with smooth inputs [Sojka and Schunk, 1987; Rasmussen et al., $1986 a$ ]. In this study, the HM-BC model does not have a strong enough electric field to reproduce the structures observed along the first two orbits shown in Figure 5. Density structure B' in the 2210 UT pass (Figure 5, bottom panel) is a larger feature. Towards the end of the quiet period, the IMF $B_{z}$ component approached zero, and hence, the actual convection pattern must have changed. This density feature may well be the equivalent of the TDIM density enhancement from 2220 to 2223 UT in the same orbit panel of Figure 5. The B' density structure is certainly not a precipitation feature (Figure 4), since no appreciable precipitation is present.

The $\mathbf{C}$ arrows in Figure 5 highlight the third region where differences are present between the modelled and observed densities. In this case, the differences are not systematic and are not present in all cases. This region is the afternoon sector trough. Here, the depleted trough densities are associated with a combination of the convection-corotation balance and the presence of the auroral equatorward boundary [Sojka et al., $1981 a$ ]. For the orbit at 1400 UT, an almost perfect agreement is found in the densities (Figure 5) and the convection (Figure 3 ), while for the orbit at 2210 UT, the observed trough is significantly more poleward and a similar difference is seen in the convection at that time. Hence, the differences highlighted by the $\mathrm{C}$ arrows are probably associated with the electric field variability not present in the HM-BC convection model. At present, there are no methods available to reconstruct the variability in the electric field data.

What about the "substorms"? In Figure 5, the 0735 UT pass occurred during the substorm period. However, it does not look especially different from the other orbits. Neither the convection (Figure 3) nor the precipitation (Figure 4) appear significantly more disturbed. Nevertheless, the DE 1 SAI data 

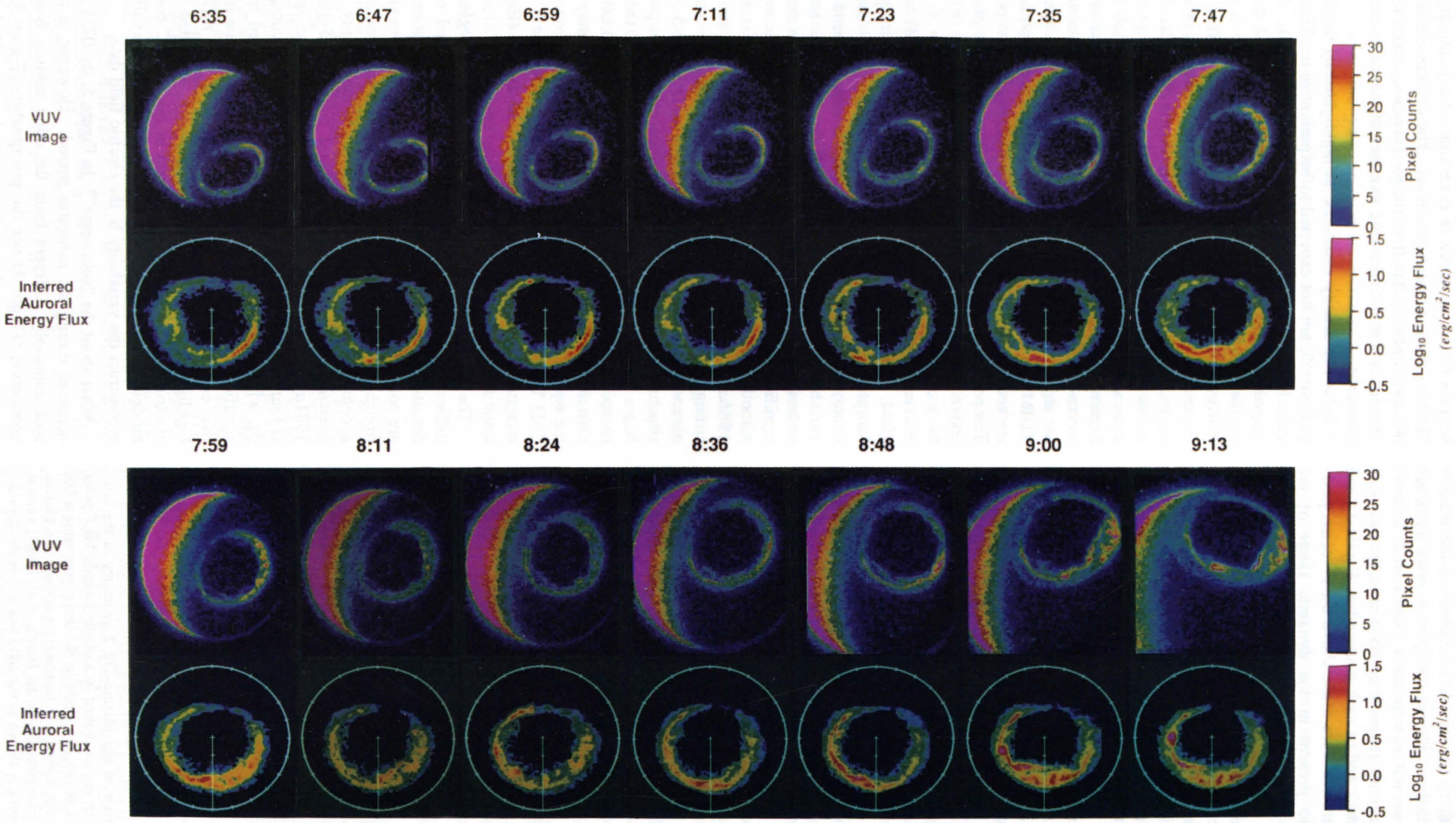

Plate 2. Fourteen DE 1 VUV auroral images and the inferred auroral energy fluxes during the substorm period on November 22, 1981. The top panel in each pair is the VUV compressed count rate image, while the lower panel is the energy flux in the same polar plot used in Plate 1. Color keys are given on the right side of each row. 
do show significant differences in the precipitation during this time. The next section looks at this substorm period in depth.

\section{THE 0635-0935 UT SUBSTORM PERIOD}

\subsection{Auroral Imagery}

The high-altitude satellite DE 1 obtained continuous sequences of auroral images in time intervals in excess of 4 hours for some orbits during the fall of 1981 . The satellite is equipped with a spin-scan auroral imager that comprises three scanning photometers with off-axis parabolic reflectors as the primary optical elements. Two of these imaging photometers provide global auroral images at visible wavelengths, each utilizing any of 12 filters selected by ground command. The third photometer is capable of auroral imaging at vacuum ultraviolet (VUV) wavelengths with a similar selection of one of its 12 filters. In typical operation, a $30^{\circ} \times 120^{\circ}$ image is obtained every $12 \mathrm{~min}$ for each photometer. The images are centered in the Earth nadir direction, with the $30^{\circ}$ angular width of each image aligned transverse to the plane of satellite rotation and the coplanar satellite orbital plane. A detailed description of the imaging instrumentation is given by Frank et al. [1981].

During the substorm period, images were obtained every 12 min from 0635 to 0912 UT. A total of 14 images show the auroral dynamics during this period. Images were taken simultaneously at 557 and $630-\mathrm{nm}$ in the visible spectrum and in the VUV over the 123 to $160-\mathrm{nm}$ bandwidth. On this day the 630-nm intensities were very low and because of statistical considerations were not suitable for use in the energy fluxcharacteristic energy analysis described by Sojka et al. [1989]. Plate 2 shows the VUV images for this substorm period, and the color key gives the observed SAI photometer compressed pixel counts. From these observations, the auroral dynamics is evident. In the evening and night sectors, discrete auroral forms are present over a large region and display a significant temporal variation, i.e., changes in these structures are seen from one image to the next. Substorm onsets are observed in the 0723 and then the 0836 UT images. None of these spatial or temporal features are present in the statistical auroral model used in the quiet day study.

In order for the images in Plate 2 to be used as an input to the TDIM, they must be converted to precipitating energy fluxes. The lower panels in each pair of images in Plate 2 show these energy fluxes. Sojka et al. [1989] discussed at length the procedures used to convert the SAI images to energy flux. In this study, two levels of conversion were considered: the first is the relative energy flux which conserves the auroral spatial and temporal variability, and the second is the absolute energy flux calibration. As has been noted by Sojka et al. [1989] and others [Rees et al., 1988], the second part is extremely difficult to do from first principles. The procedure used here is to obtain the relative auroral dynamics (spatial and temporal) from the images and then to scale the energy fluxes to achieve consistency with the LAPI data. This follows the general procedures described by Sojka et al. [1989]. The energy fluxes were computed from the VUV images by the algorithm described by Rees et al. [1988]. These energy fluxes were within a factor of 2 of the LAPI energy fluxes, which statistically was the same as was found by Sojka et al. [1989]. Hence, the same scaling factor was used to scale all the computed image energy fluxes to the LAPI level. The resulting energy fluxes are shown in the lower panel of each pair in Plate 2 with a color key in ergs per square centimeters per second. The 14 images span the entire image period, and during this time the auroral region undergoes significant changes. The $A E$ index peaks at 0800 and again at $0930 \mathrm{UT}$, which roughly correspond to the times of maximum expansion in the substorms.

\subsection{Substorm Density Comparison}

The TDIM was rerun using energy fluxes obtained from DE 1 images to simulate the ionospheric response to the auroral dynamics during the substorm period. From Figure 1 it can be argued that prior to about 0635 UT the auroral conditions were quiet, i.e., the $A E$ index was relatively small and varied smoothly. On this basis, the previous quiet day TDIM densities were used as the initial conditions at 0635 UT for the substorm simulation. During the substorm period, insufficient data were available to define a dynamic convection model, and hence, the HM-BC model was used again. Therefore, only the auroral inputs were changed for the substorm simulation. The Hardy empirical auroral model was replaced with a timevarying sequence of image energy fluxes. These images occur at 12-min intervals. In using the image energy fluxes, each was assigned an image UT (the middle of its 12 -min period) and then energy fluxes at a given location were obtained by linearly interpolating between two images that occurred before and after the required TDIM UT.

In creating the dynamic auroral model from the SAI images, it was difficult to infer the characteristic energy of the precipitation on this day. This is because the characteristic energy is deduced from the ratio of emissions at different wavelengths. The $630-\mathrm{nm}$ emission is crucial for this ratio calculation. As was already pointed out, the 630-nm had low count rates; hence, these data could not constrain this parameter. The computed ionospheric densities do, however, depend upon the characteristic energy. In the appendix a parametric study of this dependence is given. On the basis of the limited data available, we adopted a characteristic energy model; the SAI images, the LAPI data, and the Hardy et al. [1985] characteristic energies were used to define this model. The model defines the characteristic energy in the polar cap to be $1 \mathrm{keV}$ and equatorward of the oval to be $5 \mathrm{keV}$. Inside the oval in the morning sector it is also $5 \mathrm{keV}$, while in the afternoon-evening oval it is $3 \mathrm{keV}$. In this model the oval is defined as regions where the energy flux exceeded $0.5 \mathrm{erg} \mathrm{cm}-2$ $\mathrm{s}^{-1}$.

Figure 7 compares the substorm TDIM ("adopted $\mathrm{E}_{\mathrm{o}}$ " line), the quiet day TDIM ("original simulation" line), and the LANG observations for the 0735 UT DE 2 pass. The modelmeasurement discrepancy in the dawn sector trough is, as expected, unchanged. In the polar cap, especially the dusk sector, the new model densities are in significantly better agreement with the LANG observations. However, the earlier similarity between model and data in the dusk sector trough is changed, and now there is a marked difference in densities. The substorm TDIM (adopted $\mathrm{E}_{\mathrm{o}}$ ) densities are almost an order of magnitude larger than the LANG trough densities, whereas the quiet day TDIM densities were only a factor of 2 larger than the LANG densities. This feature is significant and will be discussed in the following section. A second northern hemisphere DE 2 LANG pass occurred later in the substorm period. Figure 8 shows the LANG density (crosses), as well as 


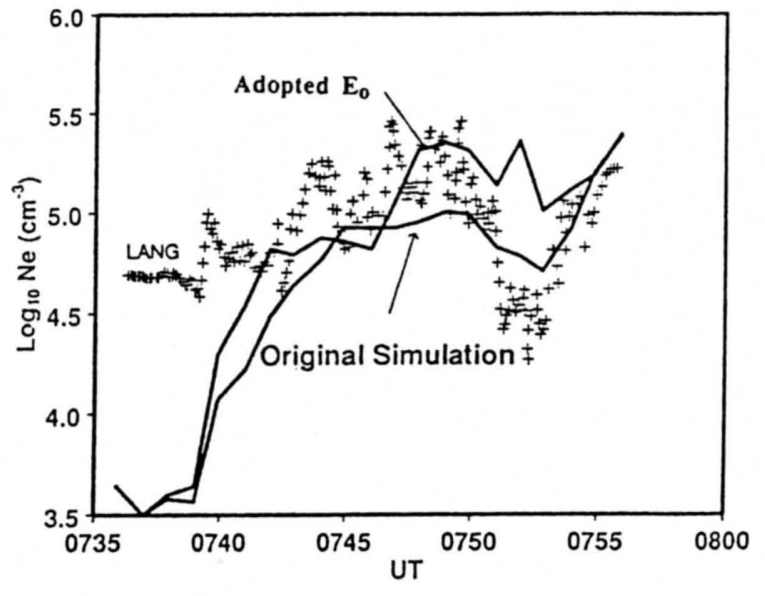

Fig. 7. Electron density comparison during the 0735 UT substorm on November 22, 1981. The DE 2 LANG data (crosses) are compared with the TDIM simulations. Two TDIM simulations are shown, the original (from Figure 5) and the storm case labeled "adopted $E_{0}$."

the quiet day (solid line, original simulation) and substorm (solid line, adopted $\mathrm{E}_{\mathrm{o}}$ ) simulation densities. This pass occurred between 0915 and 0935 UT, which was toward the end of the image sequence and at the time of the second peak in the $A E$ index (see Figure 1). Because several hours have elapsed since the beginning of the substorm, the simulation is independent of the initial quiet conditions. This is in contrast to the pass at 0735 UT which occurred near the beginning of the image sequence. In Figure 8 the substorm simulation shows significantly better agreement with the observed densities. It lacks the sharp polar cap density structures, but this is to be expected owing to the lack of convection structure in the model. As with Figure 7, the biggest disagreement occurs in the dusk sector auroral oval-trough region. In this case, the trough minimum is matched reasonably well; however, the model predicts a huge density maximum in the oval at 0928 UT. The following section describes in depth how the discrepancy in Figure 7 arose. The argument to be presented also applies to the density difference shown in Figure 8.

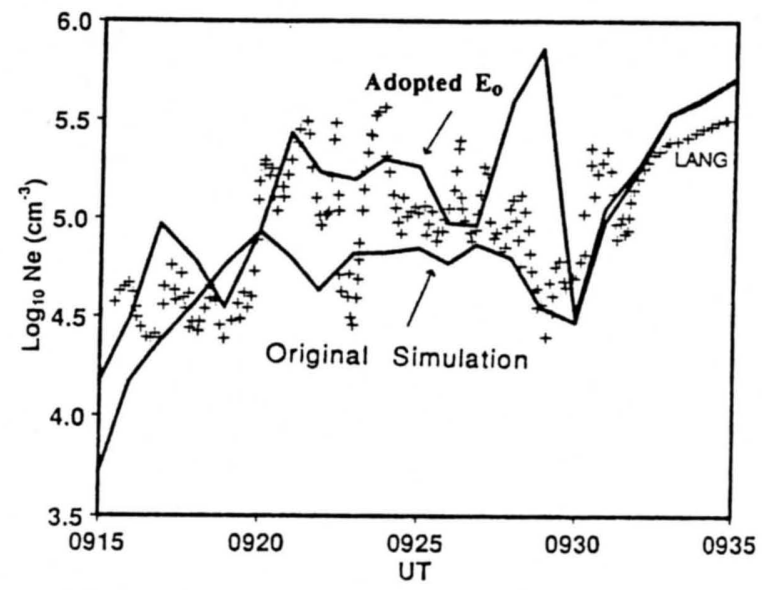

Fig. 8. Second substorm electron density comparison on November 22, 1981. The DE 2 LANG data (crosses) are compared with the TDIM simulations. The figure layout is identical to that of Figure 7.

\subsection{Substorm Discussion}

The density comparison in the polar regions indicates that the dynamic auroral TDIM simulation yields a better agreement with the data (see Figure 7). However, of concern is the larger discrepancy produced in the dusk sector trough. In order to understand this, Figure 9 is used to graphically display the plasma mechanisms leading to this greater difference. The circle indicates the region where the substorm TDIM produced the larger densities. This region lies in a region of auroral emissions, as indicated by the shaded region in Figure 9. In comparison, the original oval does not coincide with this circle (compare Figure 9 with Figure 6 or 2). Hence, the images show that during the substorm period, auroral precipitation extends considerably more equatorward in this local time sector than predicted by the statistical oval. In fact, this interpretation is consistent with the LAPI data which show strong precipitation equatorward of the statistical oval (see Figure 4, the 0735 UT pass at about 0753 UT).

Also shown in Figure 9 are the trajectories of two plasma flux tubes that form this enhanced density region. On each trajectory the small circles mark hourly intervals. One of the trajectories (labeled "a") is for plasma convecting around from the dayside and stagnating in the circle. This trajectory is responsible for the high TDIM densities because the plasma stagnates in a region of high auroral energy fluxes. However, such a scenario is extremely unlikely; stagnation occurs only in regions equatorward of the auroral oval, where the magnetospheric electric field tends to cancel the corotational electric field. Hence, the inability to dynamically modify the convection pattern during the substorm has resulted in the "spurious" high TDIM densities. Furthermore, as can be seen in Figure 7, there is almost no dusk sector trough in this substorm simulation. From this it can be deduced that the magnetospheric electric field must have penetrated to lower latitudes. The single DE 2 substorm pass at 0735 UT in Figure 3 indicates that this is the case. The second plasma flux tube

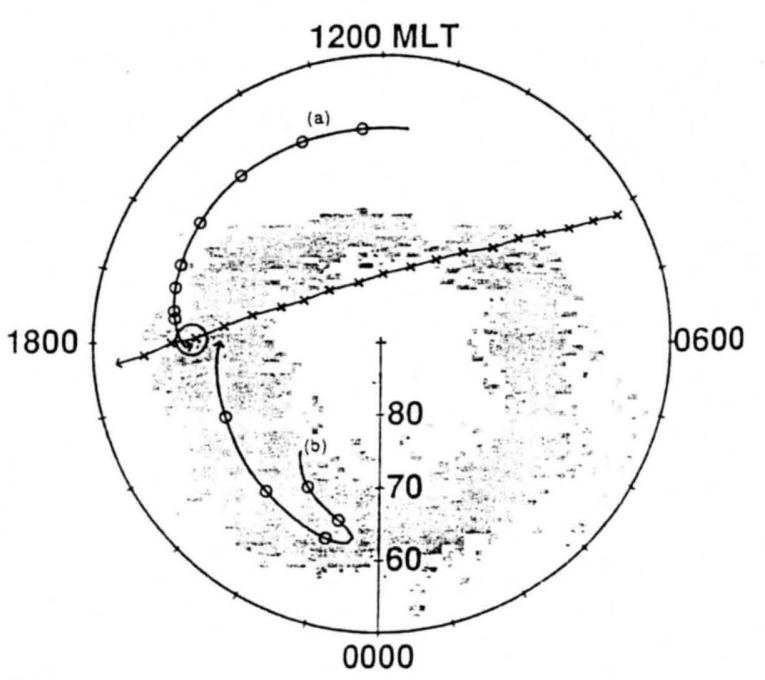

Fig. 9. Schematic view of the plasma-DE 2 geometry in the "stagnation" dusk trough region plotted in a dipole latitude-MLT polar format. This region is shown as the intersection of the solid, crossed line representing a DE 2 satellite track and the solid, circled line (labeled a) representing a plasma trajectory. The shaded region shows the auroral precipitation inferred from an appropriate DE 1 SAI auroral image $\left(>0.25\right.$ ergs $\left.\mathrm{cm}^{-2} \mathrm{~s}^{-1}\right)$. 
trajectory (labeled "b") shown in Figure 9 represents the typical poleward edge of the dusk sector trough. Here, the plasma is convecting sunward inside the oval to the region of interest. High TDIM densities are associated with this flux tube because it is in a region of high precipitation for several hours. The DE 2 orbit track at 0735 UT is superimposed on Figure 9 as the line with small crosses.

\section{SUMMARY}

In this study we have used an extensive $\mathrm{DE}$ data base to both constrain inputs to the TDIM and then check the simulated densities. This has been done for both a quiet period and a substorm period. The quiet period had a duration of about 24 hours, while the substorm duration was 3 hours and occurred 6.5 hours into the quiet period. This is the most extensive high-latitude TDIM-data comparison carried out to date. Aspects of the study can almost be regarded as looking at ionospheric "weather" rather than the usual "climatology." Such a capability can arise only when the inputs constraining the model are available with adequate resolution and coverage. Under ideal conditions the combined DE 1 and DE 2 data bases can almost achieve this resolution, as the study has shown.

The study can be summarized by the following key findings:

1. The quiet day study produced very good agreement between modelled and observed electron densities in the topside ionosphere with two important exceptions: First, across the polar region the DE 2 LANG densities showed fine structure ( $F$ layer patches) in addition to the overall regional density morphology. Such fine structure is associated with the "weather" variability in the magnetospheric inputs. These cannot be completely described by the present-day observations. The full extent of this structure is, therefore, missing from the simulated densities. Second, a surprising discrepancy arose in the pre-sunrise mid-latitude trough. The TDIM densities were an order of magnitude lower than those observed by DE 2. This discrepancy was not restricted to this day; the measured densities were similar in this region over many days. This region is also independent of the magnetospheric inputs and so does not rely on good resolution in the DE inputs. A follow-up study has been initiated to elucidate the source of this marked discrepancy.

2. The substorm study showed remarkably good agreement with the observed densities with again two exceptions. First, the observed fine structuring of the polar cap densities was even more marked during the substorm period. During a substorm, the highest degree of "weather" is present. No method of achieving both the temporal and spatial coverage is available to describe the source of this structure. Second, although the auroral image sequence produces a very good description of the global substorm, the associated convection electric field is not available. This can lead to drastic errors in the model prediction. In this case, the dusk sector stagnation occurred inside the auroral oval. The ensuing TDIM density enhancement was over an order of magnitude greater than was observed. Such a discrepancy is purely an artifact of not having the necessary electric field measurements to couple the auroral and convection patterns self-consistently.

This study shows again the importance of using extensive data bases to constrain the global and temporal behavior of the magnetospheric inputs to the ionospheric (and thermospheric) system. Even under quiet conditions, as is shown by this study, simplifying model assumptions need to be verified.
Under dynamic substorm conditions, even simple mismatching between inputs leads to major errors in calculated ionospheric densities. More work is needed in deducing an empirical means of raking convection and precipitation patterns self-consistent during temporal variations. This would be even more useful as global auroral imagery becomes a standard replacement for statistical auroral inputs. The major "weather" aspects will require not only high-resolution imagery of the precipitation, but also information concerning the structure in the convection pattern. It is the structure in the convection pattern that produces the density fine structure, as is shown simplistically in the TDIM polar cap structure of Plate 1.

\section{APPENDIX}

The depth into the thermosphere that an auroral electron can penetrate and the altitude distribution of ionization depend upon several factors. The most important factor is the energy of the electron. When a flux of electrons travels through the ionosphere, the energy is characterized not by a single value, but by the initial energy spectrum. A lengthly calculation is needed to deduce the associated altitude distribution of ionization. To simulate this process, the TDIM selects between ionization profiles for different characteristic energies, different seasons, and different solar cycle conditions. These basic ionization profiles were computed using the Strickland auroral deposition code (R. Daniel, private communication, 1988).

Figure 10 shows the sensitivity of the TDIM density calculation to the characteristic energy. The substorm simulation described in section 4 was repeated three times for three fixed characteristic energies. In each case, the energy fluxes varied as shown in Plate 2, i.e., according to the image variability. Three results for typical auroral energies are shown in Figure 10, namely 1, 3, and $5 \mathrm{keV}$. Since the densities shown in Figure 10 are along the DE 2 track used in Figure 7 , they are all in the topside ionosphere. In this region, the lowest energies contribute the most ionization, although the integrated ionization is largest for the most energetic electrons. The curves shown in Figure 10 indicate

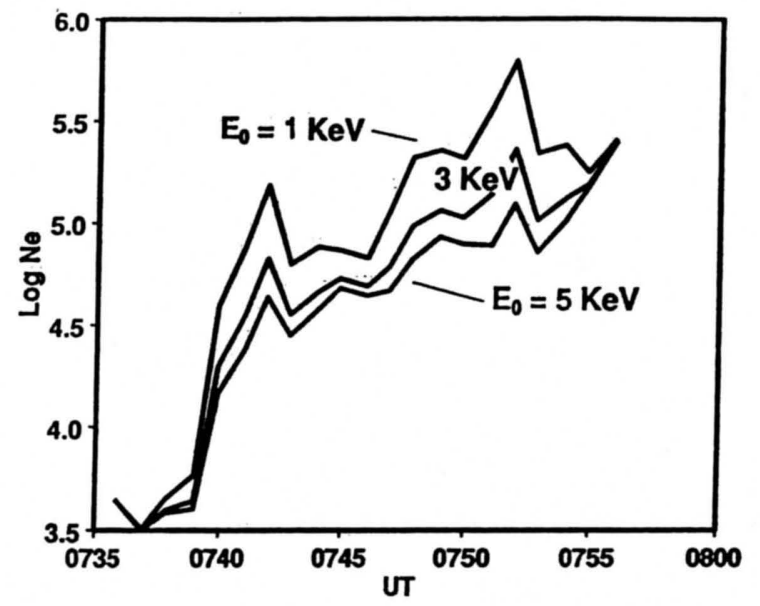

Fig. 10. Model electron density variation along the DE 2 orbit track during the 0735 UT storm period. Each curve represents the TDIM simulation for different characteristic energies. In each case, the SAI images were used to determine the energy flux for the auroral precipitation. The densities are in electrons per cubic centimeter. This is the same orbit shown in Figure 7. 
that a factor of 2 to 4 density difference can be anticipated for the expected uncertainty in the auroral electron energy.

For the adopted $E_{0}$ data shown in Figures 7 and 8, the following simple auroral characteristic energy distribution was adopted: (1) Inside the polar cap, poleward of the auroral oval magnetic latitude, $E_{0}=1 \mathrm{keV}$. (2) Inside the afternoonevening sector oval, $E_{\mathrm{o}}=3 \mathrm{keV}$. (3) Inside the morning sector oval, $E_{\mathrm{o}}=5 \mathrm{keV}$. (4) Equatorward of oval, $E_{\mathrm{o}}=5 \mathrm{keV}$. In this case the oval is defined as a region where the auroral energy flux exceeds $0.5 \mathrm{erg} \mathrm{cm}^{-2} \mathrm{~s}^{-1}$.

Acknowledgments. This research was supported by NASA grants NAGW-1547, NAGW-77 and NAG5-1484 to Utah State University, by NASA contract NAS5-33031 to Southwest Research Institute. At the University of Iowa this research was supported in part by NASA under grants NAG5-483 and NAGW-1536. The VEFI data were made available to us by J. P. Heppner and N. C. Maynard, and the IMF data were obtained from the National Space Science Data Center. The expertise of R. Dvorsky greatly simplified the auroral image analysis.

The Editor thanks R. A. Heelis and N. C. Maynard for their assistance in evaluating this paper.

\section{REFERENCES}

Conrad, J. R., and R. W. Schunk, Diffusion and heat flow equations with allowance for large temperature differences between interacting species, J. Geophys. Res., 84, 811-822, 1979.

de la Beaujardière, O., V. B. Wickwar, G. Coudal, J. M. Holt, J. D. Craven, L. A. Frank, L. H. Brace, D. S. Evans, J. D. Winningham, and R. A. Heelis, Universal time dependence of nighttime $F$ region densities at high latitudes, J. Geophys. R`s., SO, 4319-4332, 1985.

Evans, D. S., Global statistical patterns of :uroral phenomena, in Quantitative Modelling of Magnetosphere-Ionosphere Coupling Processes, pp. 325-330, Kyoto Sangyo University, Kyoto, Japan, 1987.

Frank, L. A., J. D. Craven, K. L. Ackerson, M. R. English, R. H. Eather, and R. L. Carovillano, Global auroral imaging instrumentation for the Dynamics Explorer mission, Space Sci. Instrum., 5, 369-393, 1981.

Fuller-Rowell, T. J., D. Rees, S. Quegan, R. J. Moffett, and G. J. Bailey, Interactions between neutral thermospheric composition and the polar ionosphere using a coupled ionosphere-thermosphere model, $J$. Geophys. Res., 92, 7744-7748, 1987.

Hardy, D. A., M. S. Gussenhoven, and E. Holeman, A statistical model of auroral electron precipitation, J. Geophys. Res., 90, $4229-4248$, 1985.

Hedin, A. E., MSIS-86 thermospheric model, J. Geophys. Res., 92, 4649-4662, 1987.

Heelis, R. A., J. K. Lowell, and R. W. Spiro, A model of the high-latitude ionospheric convection pattern, J. Geophys. Res., 87, 6339-6345, 1982.

Heppner, J. P., and N. C. Maynard, Empirical high-latitude electric field models, J. Geophys. Res., 92, 4467-4489, 1987.

Krehbiel, J. P., L. H. Brace, R. F. Theis, W. H. Pinkus, and R. B. Kaplan, The Dynamics Explorer Langmuir probe instrument, Space Sci. Instrum., 5, 493-502, 1981.

Maynard, N. C., E. A. Bielecki, and H. F. Burdick, Instrumentation for vector electric field measurements from DE-B, Space Sci. Instrum., 5, 523-534, 1981.

Maynard, N. C., J. P. Heppner, and A. Egeland, Intense variable electric fields at ionospheric altitudes in the high-latitude regions as observed by DE-2, Geophys. Res. Lett., 9, 981-984, 1982.

Rasmussen, C. E., R. W. Schunk, and J. J. Sojka, Effects of different convection models upon the high-latitude ionosphere, J. Geophys. Res., 91, 6999-7005, 1986a.

Rasmussen, C. E., R. W. Schunk, J. J. Sojka, V. B. Wickwar, O. de la Beaujardière, J. Foster, J. Holt, D. S. Evans, and E. Nielsen, Comparison of simultaneous Chatanika and Millstone Hill observations with ionospheric model predicitons, J. Geophys. Res., 91, 6986-6998, 1986b.

Rees, D., and T. J. Fuller-Rowell, Seasonal and geomagnetic response of the thermosphere and ionosphere, AGARD Conf. Proc., CP.441, 21.1-21.7, 1989.

Rees, M. H., D. Lammerzheim, R. G. Roble, J. D. Winningham, J. D. Craven, and L. A. Frank, Auroral energy deposition rate, characteristic electron energy, and ionospheric parameters derived from Dynamics Explorer 1 images, J. Geophys. Res., 93, 12,841$12,860,1988$.

Rich, F. J., and N. C. Maynard, Consequences of using simple analytical functions for the high-latitude convection electric field, J. Geophys. Res., 94, 3687-3701, 1989.

Roble, R. G., E. C. Ridley, and R. E. Dickinson, On the global mean structure of the thermosphere, J. Geophys. Res., 92, 8745-8758, 1987.

Schunk, R. W., and W. J. Raitt, Atomic nitrogen and oxygen ions in the daytime high-latitude $F$ region, J. Geophys. Res., 85, 1255-1272, 1980.

Schunk, R. W., and J. J. Sojka, Ion temperature variations in the daytime high-latitude $F$ region, J. Geophys. Res., 87, 5169-5183, 1982.

Schunk, R. W., and J. C. G. Walker, Theoretical ion densities in the lower ionosphere, Planet. Space Sci., 21, 1875-1896, 1973.

Schunk, R. W., W. J. Raitt, and P. M. Banks, Effect of electric fields on the daytime high-latitude $E$ and $F$ regions, J. Geophys. Res., 80, 3121-3130, 1975.

Schunk, R. W., P. M. Banks, and W. J. Raitt, Effects of electric fields and other processes upon the nighttime high-latitude $F$ layer, $J$. Geophys. Res., 81, 3271-3282, 1976.

Sojka, J. J., and R. W. Schunk, A theoretical study of the high-latitude $F$ region's response to magnetospheric storm inputs, J. Geophys. Res., $88,2112-2122,1983$.

Sojka, J. J., and R. W. Schunk, A theoretical $F$ region study of ion compositional and temperature variations in response to magnetospheric storm inputs, J. Geophys. Res., 89, 2348-2358, 1984.

Sojka, J. J., and R. W. Schunk, A theoretical study of the global $F$ region for June solstice, solar maximum, and low magnetic activity, $J$. Geophys. Res., 90, 5285-5298, 1985.

Sojka, J. J., and R. W. Schunk, A theoretical study of the high-latitude ionosphere's response to multicell convection patterns, J. Geophys. Res., 92, 8733-8744, 1987.

Sojka, J. J., W. J. Raitt, and R. W. Schunk, A theoretical study of the high-latitude winter $F$ region at snlar minimum for low magnetic activity, J. Geophys. Res., 86, 609-621, 1981a.

Sojka, J. J., W. J. Raitt, and R. W. Schunk, Theoretical predictions for ion composition in the high-latitude winter $F$ region for solar minimum and low magnetic activity, J. Geophys. Res., 86, 2206-2216, 1981 b.

Sojka, J. J., R. W. Schunk, J. V. Evans, J. M. Holt, and R. H. Wand, Comparison of model high-latitude electron densities with Millstone Hill observations, J. Geophys. Res., 88, 7783-7793, 1983.

Sojka, J. J., C. E. Rasmussen, and R. W. Schunk, An interplanetary magnetic field dependent model of the ionospheric convection electric field, J. Geophys. Res, 91, 11,281-11,290, 1986.

Sojka, J. J., R. W. Schunk, J. D. Craven, L. A. Frank, J. Sharber, and J. D. Winningham, Modeled $F$ region response to auroral dynamics based upon Dynamics Explorer auroral observations, J. Geophys. Res., 94, 8993-9008, 1989.

Spiro, R. W., P. H. Reiff, and L. J. Maher, Precipitating electron energy flux and auroral zone conductances: An empirical model, $J$. Geophys. Res., 87, 8215-8227, 1982.

Volland, H., A model of the magnetospheric electric convection field, $J$. Geophys. Res., 83, 2695-2699, 1978.

Weber, E. J., J. Buchau, J. G. Moore, J. R. Sharber, R. C. Livingston, J. D. Winningham, and B. W. Reinisch, $F$ layer ionization patches in the polar cap, J. Geophys. Res., 89, 1683-1694, 1984.

Weber, E. J., J. A. Klobuchar, J. Buchau, H. C. Carlson, Jr., R. C. Livingston, O. de la Beaujardière, M. McCready, J. G. Moore, and G. $J$. Bishop, Polar cap $F$ layer patches: Structure and dynamics, $J$. Geophys. Res., 91, 12,121-12,129, 1986.

Winningham, J. D., J. L. Burch, N. Eaker, V. A. Blevins, and R. A. Hoffman, The low altitude plasma instrument (LAPI), Space Sci. Instrum., 5, 465-475, 1981.

M. Bowline, R. W. Schunk, and J. J. Sojka, Center for Atmospheric and Space Sciences, Utah State University, Logan, UT 84322-4405.

L. H. Brace, NASA Goddard Space Flight Center, Greenbelt, MD 20771.

J. D. Craven and L. A. Frank, Department of Physics and Astronomy, University of lowa, Iowa City, IA 52242.

J. R. Sharber and J. D. Winningham, P. O. Drawer 28510 , Southwest Research Institute, San Antonio, TX 78184.

(Received August 30, 1990; revised August 1, 1991;

accepted August 1, 1991.) 